\title{
A NEW FUNGUS GROWING ANT FROM MEXICO
}

\author{
By William F. BuREN
}

Alexandria, Louisiana

Trachymyrmex smithi, n. sp.

\section{Worker.}

Similar to T. septentrionalis obscurior but black in color and with several structural differences.

Length about 3.5 to $4.0 \mathrm{~mm}$.

Head, excluding mandibles, a little broader than long, wider behind than in front, with the hind border excised in an obtuse angle, and the sides feebly convex. Head broadest midway between the eyes and posterior corners. Clypeus broadly notched in the middle. Frontal carinæ more mesally placed than in many species of Trachymyrmex, produced laterally into subtriangular lobes in front, becoming faint behind and fading out before reaching the hind border of the head. Scapes surpassing posterior corners of head by about one fourth of their length. All funicular joints longer than broad. Antennal scrobes indistinct behind. Genal carinæ curving obliquely mesad past the level of the eyes. No postocular carinæ. Eyes hemispherical. A single short blunt spine behind each posterior corner of the head.

Thorax rather robust. Mesoepinotal impression moderately deep. Inferior pronotal spines small and lappet-shaped. Median superior pronotal spines separate and rather blunt. Lateral pronotal spines blunter than in obscurior, projecting laterally and curving slightly ventrad toward the tip. Three pairs of spines on the mesonotum. The first pair not as long as the lateral pronotal pair but blunter and more robust, broader at the base than high. The posterior two pairs of mesonotal spines much smaller and somewhat sharper. Epinotal spines slender and sharp. Rows of tubercles run forward on the epinotum from the epinotal spines to form longitudinal carinæ, and other rows of tubercles form rather feeble oblique carinæ on the pleuræ of the epinotum and mesonotum.

Petiole and postpetiole much as in obscurior but the petiole is longer, its anterior dorsal face more sloping. Postpetiole notched 
behind as in obscurior. The tubercles on petiole and postpetiole larger and more spine-like than in obscurior.

Lateral ridges and longitudinal depressions on first segment of gaster indistinct or absent.

Mandibles striate and rather shining. All other regions opaque, densely and finely punctate, giving a granular appearance. Tubercles and hooked hairs moderately numerous, about as in obscurior. The thoracic spines are abundantly covered with hairs and tubercles. No tubercles on legs, scapes, pronotum anterior to the spines, most pleural regions of the thorax, and venters of pedicel and gaster, although these parts have numerous hooked hairs. Tubercles larger on occipital lobes than on other parts of head; tubercles on vertex and hind portions of antennal scrobes often prolonged into small longitudinal ridges, or connected by ridges to form small longitudinal carinulæ. No pubescence except on funiculi.

Color entirely black except for the mandibles, tarsi, and articulations of femora and tibiæ, which are brown.

Male and female unknown.

Described from 59 specimens collected November 5 and November 8, I942, from the same nest in the desert near La Rosa, in the state of Coahuila, Mexico (Elinor Buren, collector). Holotype in the author's collection; paratypes in the author's collection and in the National Museum. The nest was of a simple crater type unlike that of turrifex or septentrionalis. The ants were extremely slow and sedate in movement even in hot sunlight. They were observed bringing in small green bits which seemed to be pieces of grass. The hard soil prevented excavation.

$T$. smithi seems most closely related to $T$. septentrionalis $o b-$ scurior Wheeler but the black color, broader, more robust head and thorax, differently shaped thoracic spines, weaker frontal carinæ, etc., seem sufficient distinctive characters.

This species is not closely related to turrifex which also occurs in northern Mexico (Vallecillo, Nuevo Leon). T. turrifex has shorter antennæ, a different color, narrower head, differently shaped frontal and genal carinæ, tubercles on legs and scapes, etc.

T. jamaicensis and its variants often approach or are similar in color to smithi, but these forms may be easily distinguished by the three prominent spines or large tubercles on each occipital lobe, the differently shaped head, eyes, thoracic spines, etc.

T. saussurei, arizonensis, and desertorum may all be distin- 
guished by their ferruginous color and various differences in shape, spinulation, and tuberculation.

I take great pleasure in dedicating this species to an outstanding American myrmecologist, Dr. M. R. Smith, of the National Museum.

I am indebted to Dr. Smith for his kindness in comparing specimens of $T$. smithi with an undescribed species of Trachymyrmex from Lower California in his possession.

The secretary of the Cambridge Entomological Club regrets to announce the death of Mr. Charles V. Blackburn at Stoneham, Mass., on April 11, 1944, in his 88th year. He was a member of the Club for 41 years, having been elected at the 232nd meeting, December 15, 1903. In 1942 he was elected an honorary member. 

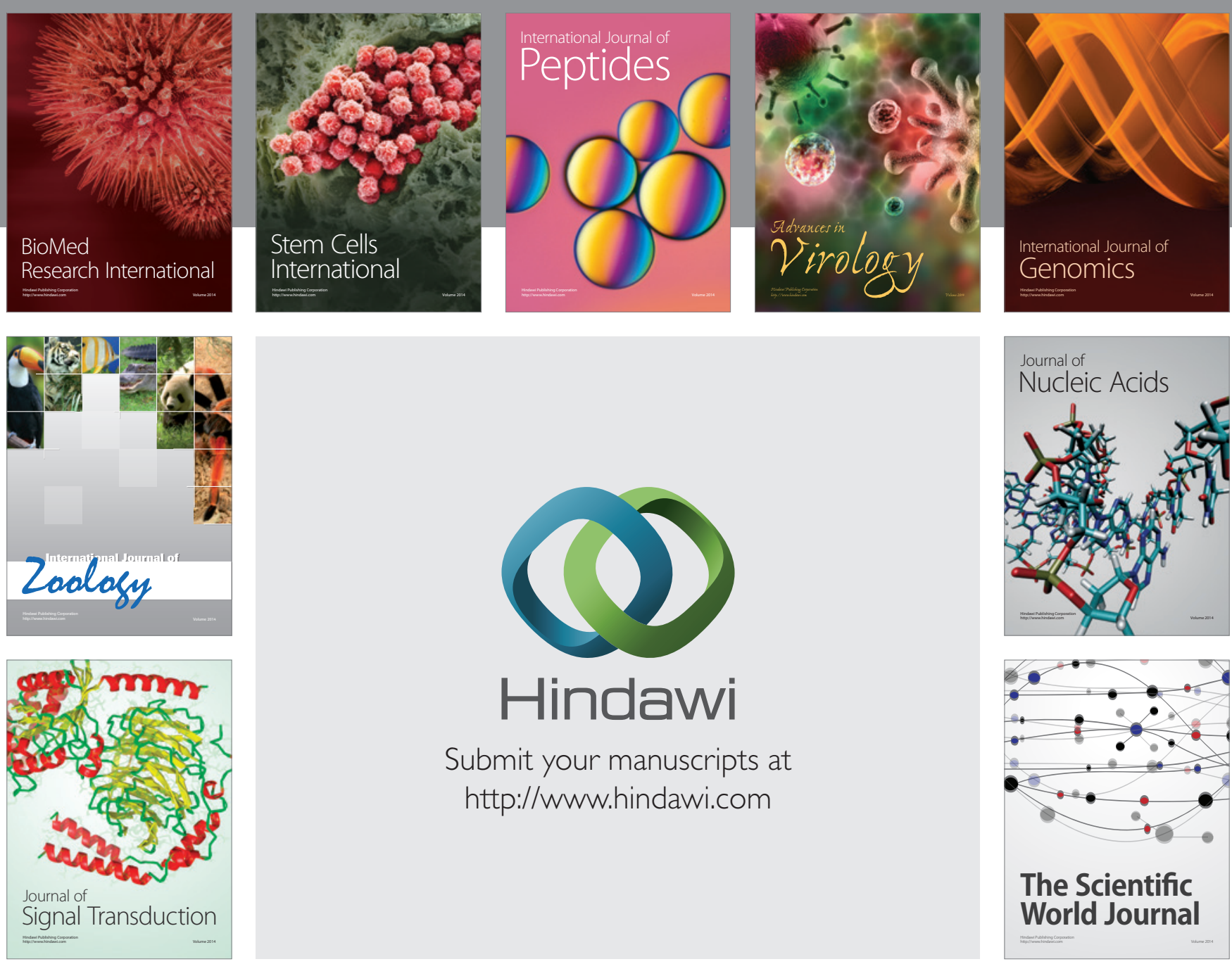

Submit your manuscripts at

http://www.hindawi.com
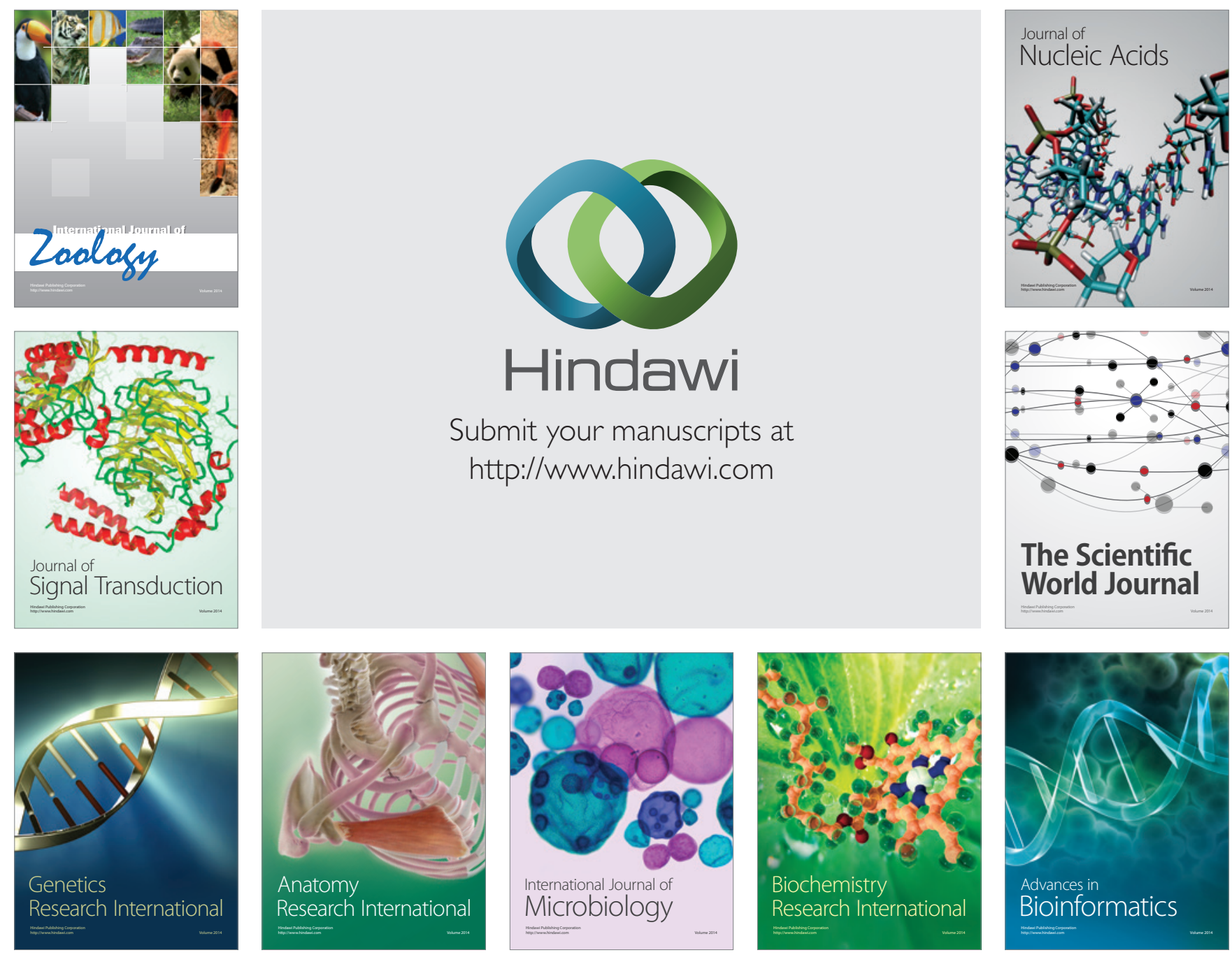

The Scientific World Journal
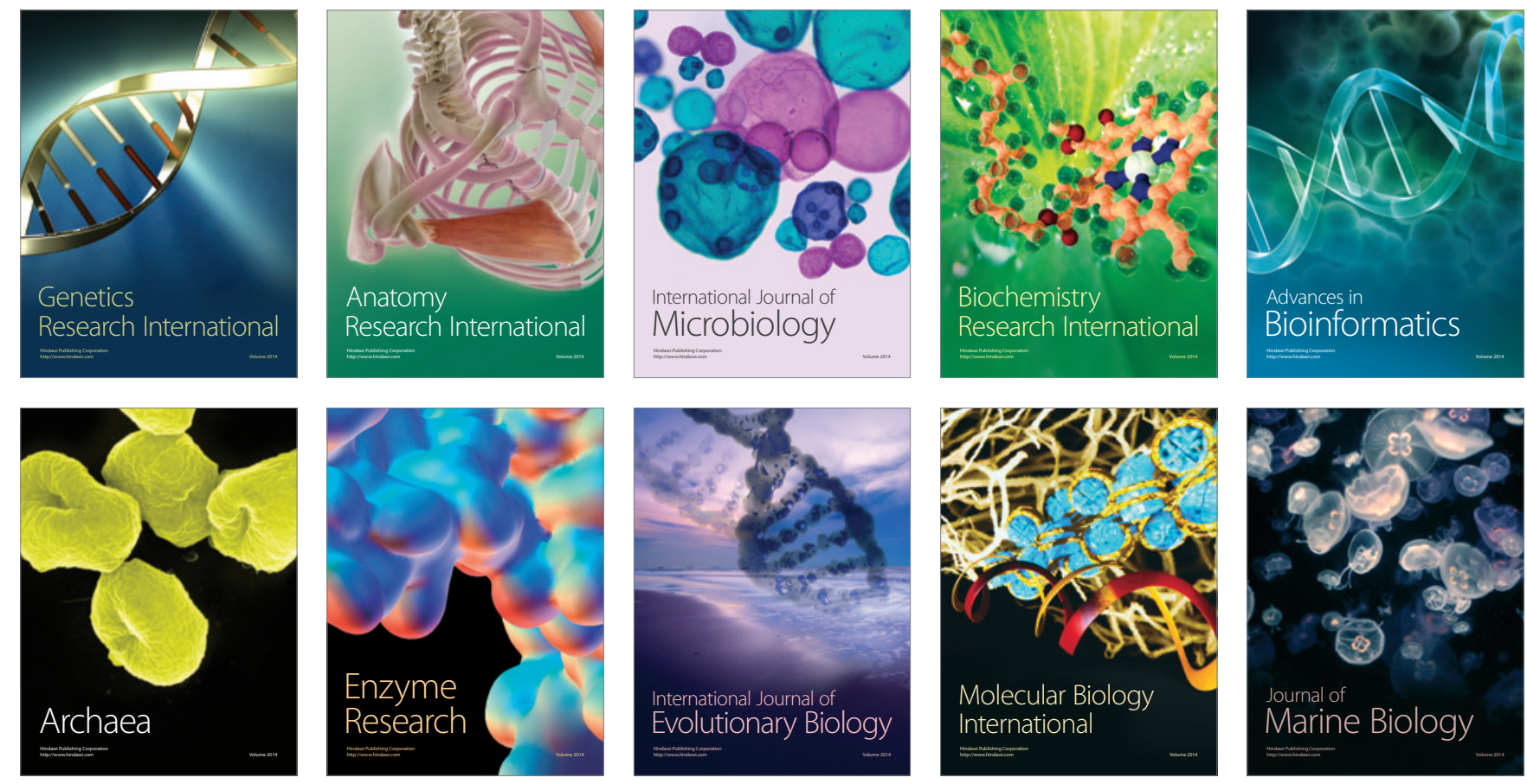